\title{
Wallerian degeneration of injured axons and synapses is delayed by a Ube4b/Nmnat chimeric gene
}

\author{
Till G.A. Mack ${ }^{1}$, Michael Reiner ${ }^{2}$, Bogdan Beirowski ${ }^{2}$, Weiqian $\mathrm{Mi}^{1}$, Monica Emanuelli ${ }^{3}$, \\ Diana Wagner ${ }^{1}$, Derek Thomson ${ }^{4}$, Tom Gillingwater ${ }^{4}$, Felipe Court ${ }^{4}$, Laura Conforti ${ }^{5}$, \\ F. Shama Fernando ${ }^{6}$, Andrea Tarlton ${ }^{7}$, Christian Andressen $^{2}$, Klaus Addicks ${ }^{2}$, Giulio Magni ${ }^{3}$, \\ Richard R. Ribchester ${ }^{4}$, V. Hugh Perry ${ }^{8}$ and Michael P. Coleman ${ }^{1,6}$
}

\footnotetext{
${ }^{1}$ Center for Molecular Medicine (ZMMK) and Institute for Genetics, University of Cologne, Zuelpicher Strasse 47, D-50674 Cologne, Germany

${ }^{2}$ Department of Anatomy I, University of Cologne, Joseph-Stelzmann Strasse 9, D-50931 Cologne, Germany

${ }^{3}$ Institute of Biochemistry, University of Ancona, Via Ranieri, 60131 Ancona, Italy

${ }^{4}$ Department of Neuroscience, University of Edinburgh, 1 George Square, Edinburgh, EH8 9JZ, UK

${ }^{5}$ Molecular Neurobiology Laboratory, Mario Negri Pharmaceutical Research Institute, Via Eritrea, 62, 20157 Milan, Italy

${ }^{6}$ Department of Pharmacology, University of Oxford, Mansfield Road, Oxford, OX1 3QT, UK

${ }^{7}$ Department of Biochemistry, University of Oxford, South Parks Road, Oxford, OX1 3QU, UK

${ }^{8}$ School of Biological Sciences, University of Southampton, Biomedical Sciences Building, Southampton, SO16 7PX, UK

Correspondence should be addressed to M.P.C. (michael.coleman@uni-koeln.de)
}

Published online: 19 November 2001, DOI: 10.1038/nn770

\begin{abstract}
Axons and their synapses distal to an injury undergo rapid Wallerian degeneration, but axons in the $\mathrm{C} 57 \mathrm{BL} / \mathrm{Wld}^{\mathrm{S}}$ mouse are protected. The degenerative and protective mechanisms are unknown. We identified the protective gene, which encodes an $\mathrm{N}$-terminal fragment of ubiquitination factor $\mathrm{E} 4 \mathrm{~B}$ (Ube4b) fused to nicotinamide mononucleotide adenylyltransferase (Nmnat), and showed that it confers a dose-dependent block of Wallerian degeneration. Transected distal axons survived for two weeks, and neuromuscular junctions were also protected. Surprisingly, the Wld protein was located predominantly in the nucleus, indicating an indirect protective mechanism. Nmnat enzyme activity, but not $\mathrm{NAD}^{+}$content, was increased fourfold in $\mathrm{Wld}^{5}$ tissues. Thus, axon protection is likely to be mediated by altered ubiquitination or pyridine nucleotide metabolism.
\end{abstract}

The distal segment of an injured nerve normally undergoes Wallerian degeneration within $24-48$ hours $^{1}$. Axon death in diverse neurodegenerative diseases follows the same final pathway. The earliest observable events, disruption of the cytoskeleton and blebbing of the axolemma, occur within the axon itself, whereas later stages also involve the reaction of other cell types, such as Schwann cells and macrophages. It is not known how Wallerian degeneration is initiated, but the mechanism is clearly distinct from neuronal cell body degeneration ${ }^{2,3}$.

Remarkably, central and peripheral nervous system axons in the slow Wallerian degeneration mutant mouse, C57BL/Wld ${ }^{\mathrm{S}}$, survive several weeks after transection ${ }^{4-6}$. The neuroprotective phenotype is dominant ${ }^{5}$ and intrinsic to the axon ${ }^{2,7,8}$. Thus, an unknown protective factor should exist in $W l d^{S}$ axons even before nerve transection, as the protected distal segment of axon is isolated from sites of protein translation. The existence of the putative regulatory molecule suggests that Wallerian degeneration is not a passive process, as previously thought, but an active one that removes damaged axons ${ }^{8}$. How this degenerative process is prevented in healthy axons, and thus the nature of the process itself, should follow from the identification of the Wld gene.
Wallerian degeneration has a prominent causative role in a spectrum of human neuropathologies. Axon loss occurs not only in traumatic disorders such as spinal cord injury ${ }^{9}$, but is an early event in numerous neurological disorders of diverse etiology, such as amyotrophic lateral sclerosis ${ }^{10}$, multiple sclerosis ${ }^{11}$ and toxic neuropathy ${ }^{12}$. The $W l d^{S}$ mutation protects also from vincristine toxicity ${ }^{13}$ and its potential for protection of axons in diverse neurological diseases is an area of considerable current interest. Protection of neuronal cell bodies often fails to prevent neurological disease ${ }^{14,15}$, so it is also important to find ways to protect axons. Thus, the Wld gene may open a new avenue for therapeutic strategies.

An $85-\mathrm{kb}$ tandem triplication ${ }^{16}$ has been characterized within the $W l d^{S}$ region on distal mouse chromosome 4 (ref. 17). This led to the discovery of a chimeric gene containing the $5^{\prime}$ end of $U b e 4 b$ and a gene of previously unknown function, D4Cole $1 e^{18}$. Both parent proteins are also expressed in $W l d^{S}$ mice. The human homolog of D4Cole1e (F.S. Fernando, unpublished data) is identical to human NMNAT ${ }^{19}$, a key enzyme in the synthetic pathway of $\mathrm{NAD}^{+}$(ref. 20). Although the chimeric gene is the most plausible candidate for $W l d$, the triplication also directly affects retinol binding protein $7(R b p 7)$ and could exert a position effect 

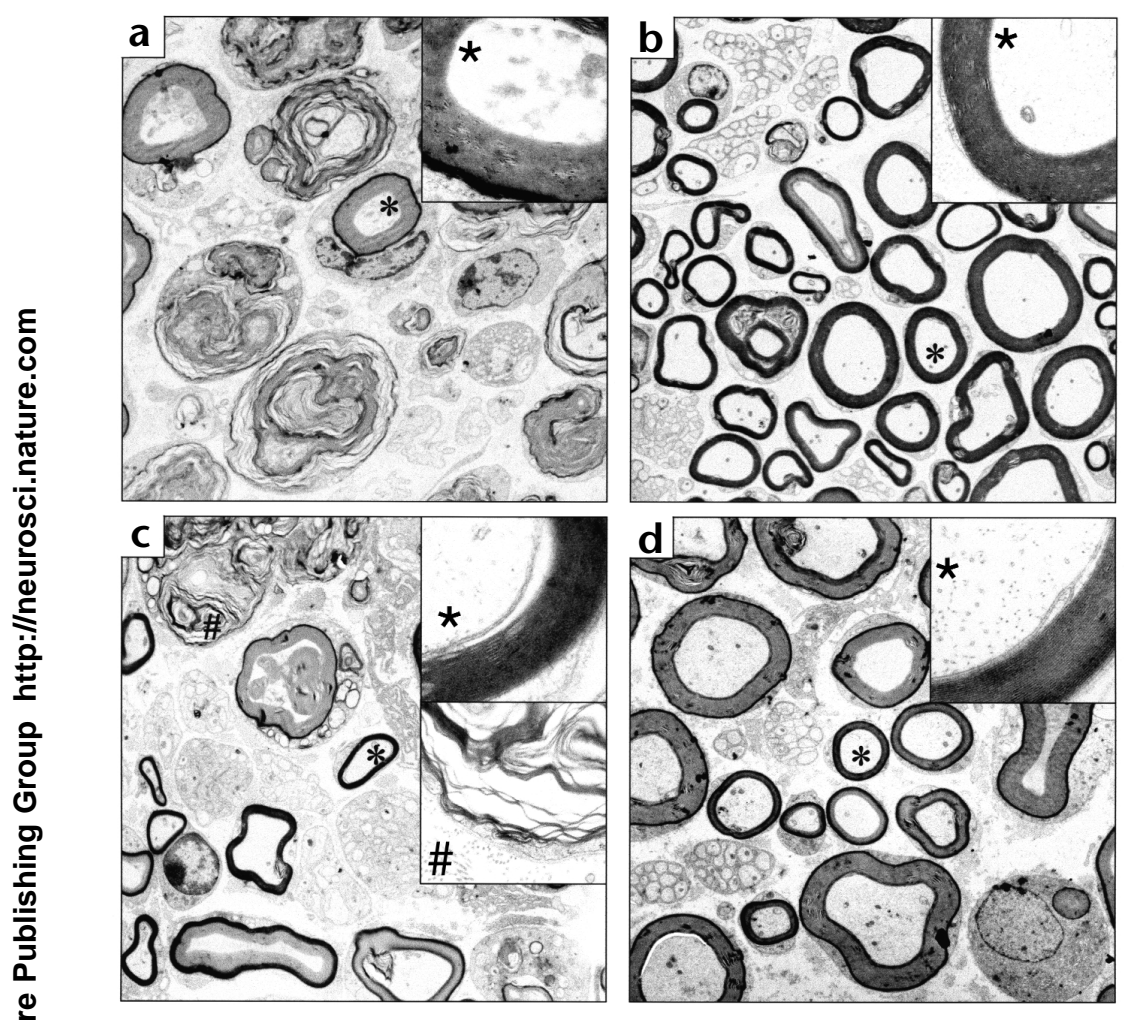

on nearby genes. Indeed, mutation of the human homolog of one neighboring gene, kinesin family $1 \mathrm{~b}(\text { Kif } 1 b)^{21}$, causes axon loss in Charcot-Marie-Tooth disease type $2 \mathrm{~A}^{22}$.

To test the hypothesis that the Ube4b/Nmnat chimeric gene confers the slow Wallerian degeneration phenotype, we expressed it in transgenic mice. The Wld $d^{S}$ phenotype was reproduced fully in one line and partially in other lines according to transgene expression level, thus proving that the chimeric gene is the Wld gene. We detected Wld protein in nuclei of neurons but neither in axons nor in Schwann cells, implicating the existence of downstream factor(s) that mediate the protective effect. Further, we report that the Wld protein showed Nmnat enzyme activity and acted in a strongly dose-dependent manner.

\section{Results}

\section{Generation of transgenic mice}

To test the role of the Ube $4 b / N m n a t$ chimeric gene, we generated transgenic mice expressing the Ube $4 b / N m n a t$ cDNA from a

Fig. 2. Physiological and morphological evidence for preservation of axons and neuromuscular junctions. Intracellular recordings (a, b), vital staining (c, d) and immunostaining (e, $\mathbf{f})$ in isolated transgenic muscles. (a) Homozygous 4836 FDB, 3 days after axotomy; (b) hemizygous 4836 FDB after 2 days. (c, d) Lumbrical muscles from 4836 hemizygote, 3 days after axotomy (c); 4836 homozygote, 5 days after axotomy (d) vitally stained with FMI -43 , which indicates intact synaptic transmission mechanisms, together with TRITC- $\alpha$-bungarotoxin staining of acetylcholine receptors. (e, f) Immunostaining for neurofilament/SV2 (FITC) and TRITC- $\alpha$-bungarotoxin. (e) 4836 homozygous lumbrical muscle, 5 days after axotomy, showing occupied endplates and some axon swelling. (f) Confocal stereo pair of 5-day axotomized 4836 homozygous lumbrical muscle showing almost fully occupied endplates (left and right), partially occupied (second right) and junction with only a slender axonal filament tipped by a 'retraction bulb' (second left). Scale bar, $20 \mu \mathrm{m}$ (c-e); $50 \mu \mathrm{m}$ (f).
Fig. I. Preserved axon ultrastructure in distal sciatic nerve 5 days after transection. Electron micrographs $(3,400 \times)$ of transverse thin sections of lesioned sciatic nerve $2-4 \mathrm{~mm}$ distal to the lesion site after 5 days. (a) Wild-type, (b) 4836 homozygote, (c) 4830 homozygote (d) WId homozygote. Insets, 20,000 $\times$ magnifications of axons marked by asterisk (top inset) and '\#' (bottom inset) from main images.

$\beta$-actin promoter. Four transgenic lines (4830, 4836,4839 and 4858 ) expressed the protein from multi-copy integrations. The transgene expression level increased in the order $4839<4830 \approx 4858<$ $W l d^{S} \approx 4836$ (Fig. 3 ). Line 4858 , whose expression level and phenotype was similar to line 4830 , is not discussed further. Like spontaneous $W l d^{S}$ mice, transgenic mice up to at least one year old showed no unusual overt phenotype.

Structural preservation of transected axons First we tested the structural preservation of axons following unilateral sciatic nerve transection, analyzing a nerve segment $2-4 \mathrm{~mm}$ distal to the lesion after 3-5 days. Electron microscopy revealed that almost all axons in line 4836 homozygotes, separated from their cell bodies for five days, contained fully preserved cytoskeleton (Fig. 1 and Supplementary Fig. 1, available on the Nature Neuroscience web site), thus successfully reproducing the $W l d^{S}$ phenotype. In contrast, all myelinated and unmyelinated wild-type axons showed clear signs of degeneration. Line 4830 axons were partially protected in accordance with the lower transgene expression level in this line (Fig. 3a) and line 4839 homozygotes also showed partial protection after
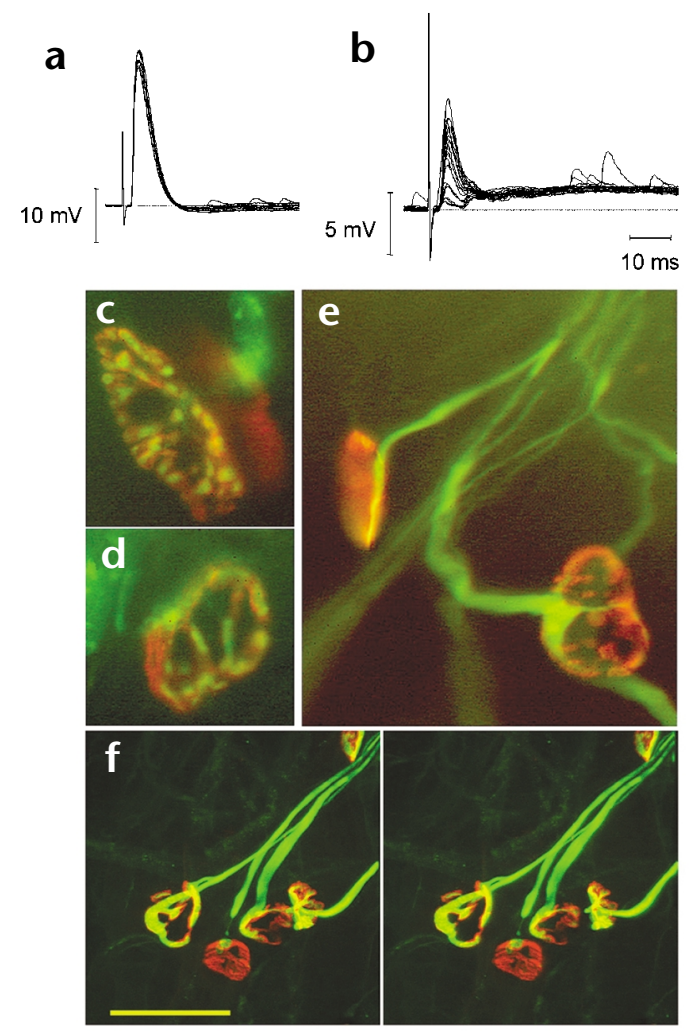

nature neuroscience $・$ volume 4 no $12 \cdot$ december 2001 
Fig. 3. Dose-dependence of axon protection by the WId gene. (a) Top, western blot showing the extent of 200-kD neurofilament protein degradation in distal sciatic nerve 3 days after transection ( 5 days for 4836 and Wld ${ }^{S}$ homozygotes). Complete preservation of NF-200 in uncut contralateral nerve (lane I) indicated degradation occurred only in vivo. Middle, western blot showing the expression level of the Wld protein in brain homogenates (detected by N70 antiserum). Bottom, same western blot probed with control monoclonal antibody $\beta$-tub 2.1 against $\beta$-tubulin. (b) Percentage of intact myelinated axons $2-4 \mathrm{~mm}$ distal to a sciatic nerve lesion. Preserved axons were counted using light microscopy in nerve segments immediately proximal to those used in (a). Counts of $93-99 \%$ in uncut contralateral nerves confirmed that observed degeneration occurred in vivo. $n$ indicates total number of nerves counted. Mean \pm s.e.m. of the middle three scores when $n$ is odd; mean \pm s.e.m. of the middle four when $n$ is even. (c) Axon preservation as a function of the expression level of WId protein. Axon preservation after 3 (black circle), 5 (white square) and 14 (cross) days as in (b); means \pm s.e.m. where $n>I$. Wld protein expression level is the signal quantified from (a), standardized against $\beta$-tubulin and expressed as a percentage of the expression in Wld $d^{S}$ homozygotes.

three days (Fig. 3a). Presence of the $W l d^{S}$ phenotype in independent lines confirms that it is caused by the transgene rather than any integration effect. Thus, Ube4b/Nmnat is the Wld gene, and it protects both sensory and motor axons in $W l d^{S}$ and transgenic mutants. No alteration to Rbp7, Kif $1 b$ or any other gene is required to reproduce the phenotype of $W l d^{S}$ mice.

\section{Functionally competent motor axons and synapses}

Next we tested whether axons were functionally as well as structurally preserved. Nerve-muscle preparations of flexor digitorum brevis (FDB) were isolated and stimulated 2-5 days after lesion. Axotomized wild-type muscles showed no response at these time points. In axotomized transgenics, however, as in the $W l d^{S}$ mutant $^{23}$, conduction of action potentials and synaptic transmission at neuromuscular junctions persisted for at least three days (Fig. 2). In a homozygous 4836 mouse, 80\% (12/15) of muscle fibers responded to nerve stimulation three days after sciatic nerve section (for example, Fig. 2a). In another 4836 homozygote, functional innervation even after 5 days was indicated by $73 \%$ (22/30) of FDB muscle fibers showing spontaneous miniature endplate potentials (MEPP) and some responding to nerve stimulation (data not shown). Weaker, and sometimes more variable, responses indicating low quantal content were observed both in line 4836 hemizygotes (Fig. 2b) and homozygous 4830 mice. In the latter, $50 \%(12 / 24)$ and $30 \%(8 / 25)$ of fibers from two mice responded to stimulation two days after lesion. These weaker responses are in accord with the lower expression levels of the Wld protein (see below).

Axotomized 4836 nerve terminals also recycled synaptic vesicles, visualized by activity-dependent staining with the styryl dye FM1-43, both upon incubating lumbrical muscles in a depolarizing solution (Fig. $2 \mathrm{c}$ and $\mathrm{d}$ ) and upon stimulation of the distal stump of axotomized tibial nerve. Preservation of pre- and postsynaptic structures was confirmed using antibodies against NF165/SV2 and TRITC- $\alpha$-bungarotoxin respectively (Fig. 2e and f). In two line 4836 homozygotes, $87-93 \%$ of endplates ( $n=154$ and 164$)$ were occupied or partially occupied $(8 \%)$ by nerve terminals 5 days after axotomy, similar to $W l d^{S}$ mice ${ }^{23,24}$. Fewer than $50 \%(n=187$ and 210$)$ were occupied in two 4836 hemizygotes after 3 days, and fewer still in 4830 homozygotes, again reflecting the lower transgene expression.

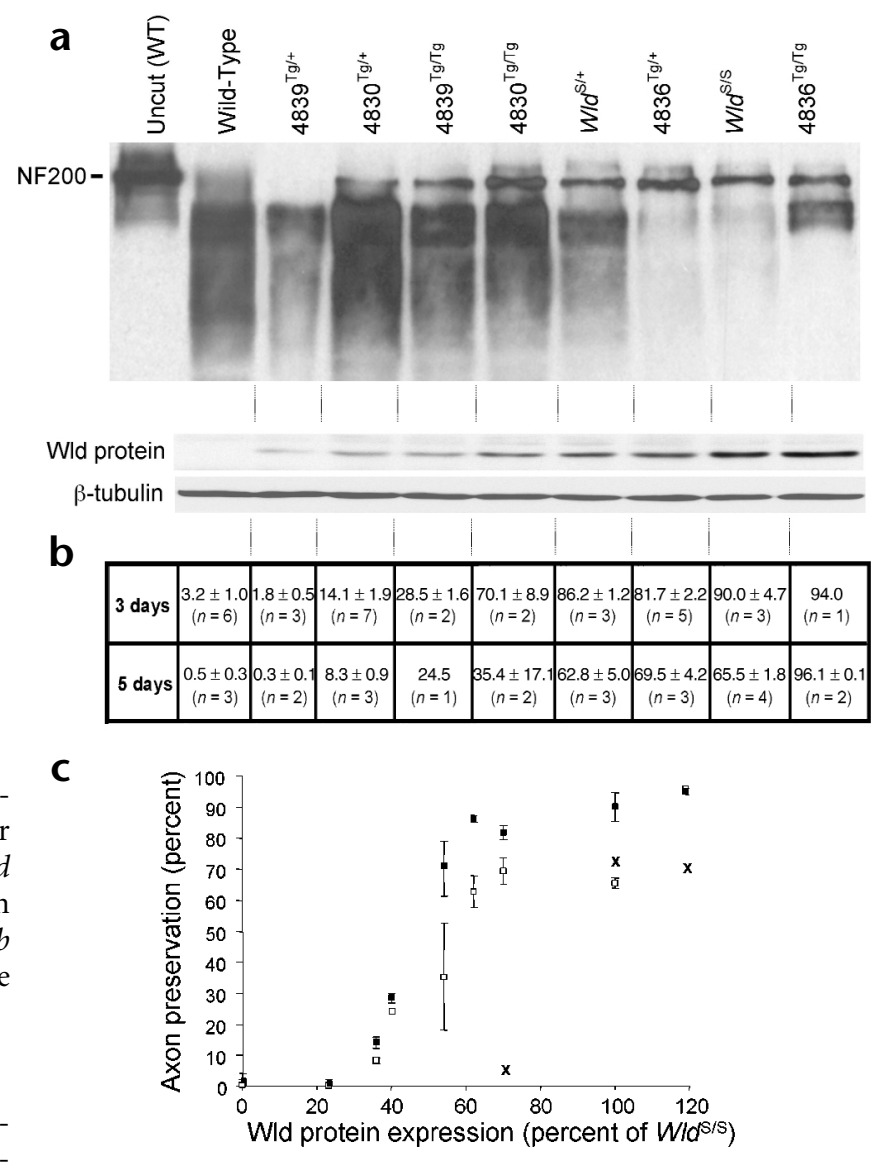

Thus, motor nerve conduction, synaptic transmission, vesicle recycling and motor nerve terminal morphology were preserved in a dose-dependent manner, with line 4836 showing a level of protection similar to $W l d^{S}$. Axons evidently persisted longer than functional motor nerve terminals, supporting the hypothesis that synaptic degeneration, at least in Wld ${ }^{S}$ mice, differs from that of axons and neuronal cell bodies ${ }^{25}$.

\section{Protection depends on WId protein expression level}

The above experiments suggested that the degree of protection depends on the expression level of Wld protein. This was surprising because heterozygous $W l d^{S}$ axons at short survival times degenerate only slightly faster than those of homozygotes ${ }^{5}$. We quantified Wld protein expression in each mutant strain to determine the level required to preserve cytoskeletal protein and axon structure for 3-5 days (Fig. 3). At lower expression levels, both measures of axon preservation indicated a strong dose-dependence. Axon counts at 3 days differed significantly between hemizygous 4836 and hemizygous 4830 mice $(p<0.001)$. Significant differences between homozygotes and hemizygotes of a single line ( $p<0.01$ for $4830 ; p<0.001$ for 4839 ) indicated that this is not a line-specific silencing effect ${ }^{26}$. Line 4839 hemizygotes were even indistinguishable from wild-type mice in neurofilament western blotting (NF-200 band, Fig. 3a), light microscopy (Fig. 3b) and electron microscopy (data not shown), despite expressing a small amount of the Wld protein (Fig. 3a). Thus, it is necessary for expression of Wld to reach a threshold level to exert a significant protective effect.

To investigate whether the protective effect of Wld protein plateaus at higher expression levels, and to test axon protection in 


\section{articles}

a
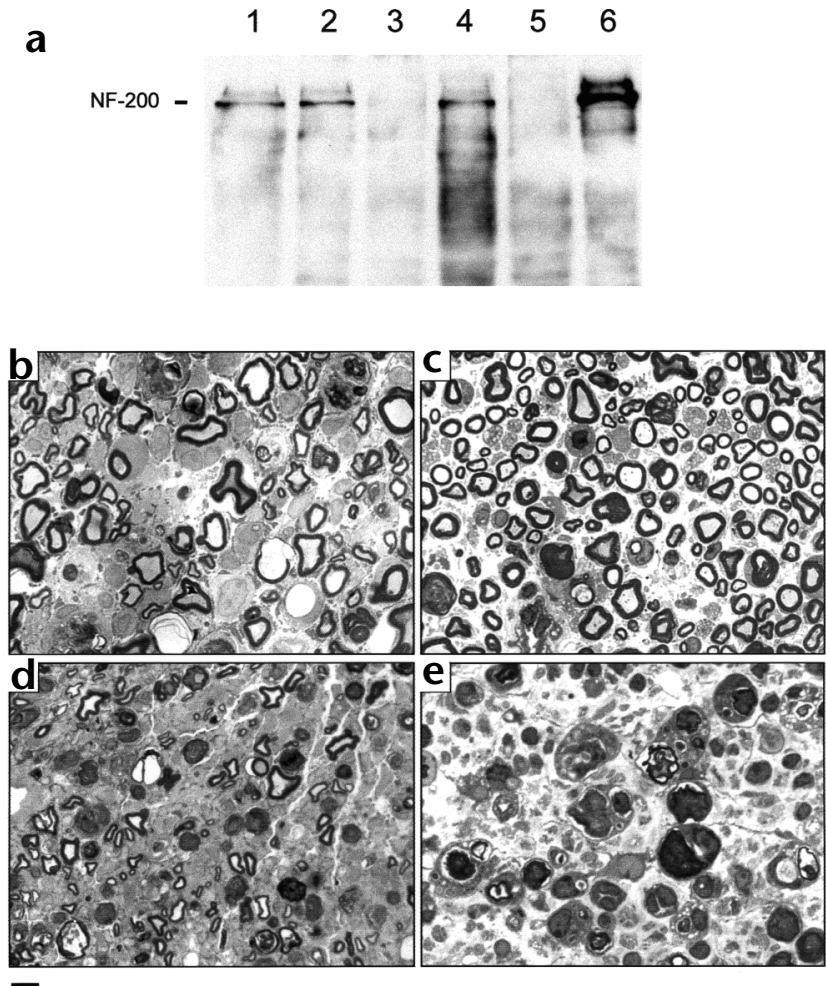

transgenic mice under still more stringent conditions, we extended these studies to post-lesion times of 10-14 days. Fourteen days after transection, protection of axons in line 4836 homozygotes (69-73\%) was as strong as that in Wld homozygotes (73-78\%; Figs. 3c and 4), again indicating full reproduction of the $W l d^{S}$ phenotype. Protection in line 4836 hemizygotes, however, was considerably weaker (35\% after 10 days and only $7 \%$ after 14 days). Thus, the extent of axon protection differed far more between 4836 homo- and hemizygotes after 14 days than after 3-5 days, indicating that dose-dependence still operates at higher Wld expression levels. It follows that if Wld protein expression could be raised still further, an even stronger protective effect than in $W l d^{S}$ and line 4836 mice could be achieved.

\section{Wld is a predominantly nuclear protein}

To determine whether the Wld protein could itself be the protective factor in axons, we determined its intracellular loca-

Fig. 5. The intracellular location of the WId protein. (a) Presence of the Wld protein in neuron nuclei of isocortex and (b) its absence from C57BL/6] control tissue. Red, anti-N70 antibody, which detects WId and Ube4b. Green, anti-MAP2 antibody markedly outlining neuronal cell bodies. (c) Absence of Wld protein (red) in astrocytes (arrows, main picture). Cytoplasmic staining in ependymal cells (central channel) of Wld $d^{S}$ thoracic spinal cord could be Ube4b. Inset, absence in astrocytes and endothelial cells (arrow) of WId $\mathrm{d}^{\mathrm{S}}$ isocortex. Green, antiGFAP. Blue, Hoechst Dye nuclear counterstain. (d-f) Confocal images of triangularis sterni muscle preparations immunostained with antiN70 antibody (green) and motor endplates counterstained with TRITC $\alpha$-bungarotoxin (red). (d) 4836 homozygote, (e) WId , (f) C57BL/6). (g-i) Motor neurons in thoracic spinal cord of both WId (g) and 4836 (h) expressed the Wld protein (red) in their nuclei, whereas those of C57BL/6) (i) did not. Cytoplasmic signals may be Ube4b or low level WId protein. Counterstain, neurofilament (green). (j-I) Red channel (WId protein plus Ube4b) images corresponding to (g-i). Scale bars, $5 \mu \mathrm{m}(\mathbf{a}, \mathbf{b}), 10 \mu \mathrm{m}$ (c), $50 \mu \mathrm{m}$ (d-l).
Fig. 4. Axon protection 10-14 days after transection. (a) Western blot showing the extent of 200-kD neurofilament protein degradation in distal sciatic nerve I0-14 days after transection. Lane I, 4836 homozygote after I 4 days; lane 2, WId ${ }^{5}$ homozygote after I 4 days; lane 3, 4836 hemizygote after 14 days; lane 4, 4836 hemizygote after 10 days; lane 5, C57BL/6] after 12 days; lane 6, C57BL/6] unlesioned. (b-e) Light microscopic images (scale bar, $10 \mu \mathrm{m}$ ) of distal sciatic nerves following transection at a more proximal site 10-14 days earlier. (b) 4836 homozygote after 14 days (corresponding intact axon count, 73\%), (c) $\mathrm{Wld}^{\mathrm{S}}$ homozygote after 14 days (73\%), (d) 4836 hemizygote after 10 days $(35 \%)$, (e) C57BL/6 J after 12 days (0\%). Electron microscopy (data not shown) indicated that cytoskeleton and myelin was preserved in 4836 and Wld ${ }^{5}$ homozygotes as in Fig. I.

tion. An antiserum labeling the N-terminal 70 amino acids of Wld protein and Ube $4 \mathrm{~b}$ detected mainly a punctate nuclear pattern in $W l d^{S}$ and transgenic neurons (Fig. 5a, c, $\mathbf{g}$ and $\mathbf{h}$ ) and this signal was absent in wild-type neurons (Fig. $5 \mathrm{~b}$ and $\mathbf{i}$ ). There was no detectable signal either in motor axon terminals (Fig. 5d-f), which can be preserved by the Wld gene (Fig. 2e and f), or in sciatic nerve axons (Supplementary Fig. 2, available on the Nature Neuroscience web site). Swollen endbulbs of 24-hour transected central and peripheral nervous system axons, which accumulate other axonal proteins, also lacked Wld protein signal (data not shown). In addition, the antibody weakly labeled the normal Ube $4 b$ protein in cytoplasm of wild-type mice, so additional labeling of any small amount of cytoplasmic Wld protein might not be distinguishable.

Although the $W l d^{S}$ phenotype is intrinsic to neurons ${ }^{2,7,8}$, Wld protein was also detected as a punctate nuclear stain in other cell types in both $W l d^{S}$ and transgenic mice (Fig. $5 \mathrm{~d}$ and e). There was no sign of Wld protein in glial cells (Fig. $5 \mathrm{c}-\mathrm{e}$ ), although previous RT-PCR (reverse transcription-polymerase chain reaction) data indicate there may be a small amount in Schwann cells ${ }^{18}$. It is highly unlikely that expression in other cell types is required

a
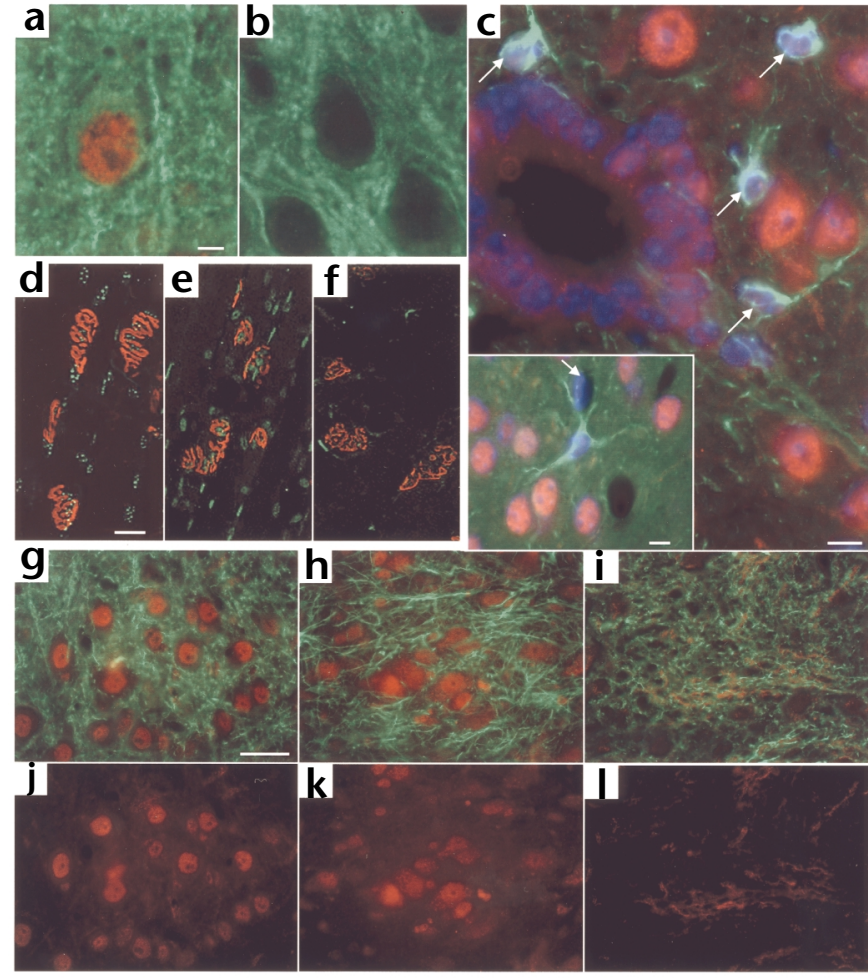

nature neuroscience $・$ volume 4 no $12 \cdot$ december 2001 
Fig. 6. $\mathrm{NAD}^{+}$metabolism in WId $\mathrm{d}^{S}$ brain. (a) Increased Nmnat activity and (b) unaltered $\mathrm{NAD}^{+}$content in WId $d^{S}$ brain. Bar charts show Nmnat specific activity and $\mathrm{NAD}^{+}$content in homogenates of fresh brain from homozygous $\mathrm{Wld}^{S}$ and $\mathrm{C} 57 \mathrm{BL} / 6 \mathrm{~J}$ mice. Means and standard error are shown $(n=3)$.

to protect axons, but it is possible that the Wld protein confers as yet unknown properties on other cell types. For example, the delayed response of $W l d^{S}$ muscles to denervation could have an intrinsic component ${ }^{27}$. We conclude that the Wld protein is predominantly located in the nucleus; thus, other factor(s) are likely to mediate the protective effect on axons.

\section{The Wld protein has Nmnat enzyme activity}

Sequence alignment with human NMNAT indicated that nucleotides 282-1140 of Wld span the entire Nmnat open reading frame. To detect any intrinsic Nmnat enzyme activity, we expressed protein recombinantly and measured the enzyme activity of the bacterial lysate. The observed specific activity for Nmnat $(0.96 \mathrm{U} / \mathrm{mg})$ was comparable with that of a bacterial lysate containing recombinant human NMNAT $(1.74 \mathrm{U} / \mathrm{mg})^{19}$. To determine whether there is a corresponding increase in Nmnat activity in $W l d^{S}$ mice, we studied Nmnat activity in brain homogenates and found a fourfold increase in $W l d^{S}$ brain compared to C57BL/6J ( $p<0.05$; Fig. 6a). The total content of $\mathrm{NAD}^{+}$, however, was not significantly altered $(p=0.2$; Fig. $6 \mathrm{~b})$. Therefore, the Wld protein confers an increase in Nmnat activity without altering the steady-state level of $\mathrm{NAD}^{+}$.

\section{Discussion}

We showed that the Ube $4 b / N m n a t$ chimeric gene is necessary and sufficient to protect injured axons for two weeks. We conclude that the Ube $4 b / N m n a t$ chimeric gene is the Wld gene, which encodes a unique neuroprotective factor for axons. It is important now to determine whether protection requires Ube $4 b$ sequences, Nmnat sequences, or both. The yeast homolog of $U b e 4 b$ is required to multi-ubiquitinate proteins ${ }^{30}$ and a direct link between ubiquitination and axon degeneration comes from the Uch-l1 mutation in gracile axonal dystrophy $^{31}$. However, the Wld protein contains only 70 of 1,173 amino acids from Ube $4 \mathrm{~b}$, and these are absent from the yeast homolog. They are therefore unlikely to confer multi-ubiquitination activity but may have a related role. The protective mechanism may be linked to the nuclear location of the Wld protein and perhaps to the non-homogeneous intranuclear distribution. Possibilities include sequestering of ubiquitination factors by protein-protein interactions and ubiquitination within the nucleus altering transcription factor stability or RNA processing, leading to an axon effect mediated by unknown proteins. Regulated nuclear transport of other ubiquitination factors can control ubiquitin-mediated degradation of nuclear substrates ${ }^{32}$. However, any Wld protein in the axon below the detection level of immunostaining could still have a direct protective role.

Nmnat is a nuclear protein and the only known mammalian enzyme catalyzing the reaction $\mathrm{NMN}+\mathrm{ATP} \rightarrow \mathrm{NAD}^{+}+\mathrm{PPi}$ (ref. 20), a reaction generally assumed not to be at equilibrium because of the constitutive action of pyrophosphatases. Thus, the increase in Nmnat activity in $\mathrm{Wld}^{\mathrm{S}}$ should increase $\mathrm{NAD}^{+}$synthesis, and the maintenance of normal steady-state levels suggests that the putative additional $\mathrm{NAD}^{+}$is metabolized. The product of a compensatory reaction could itself be involved in
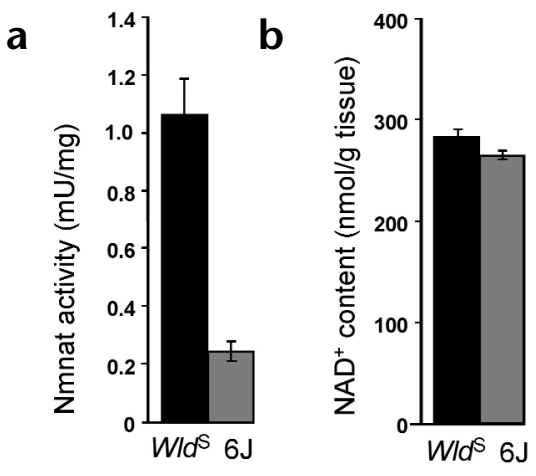

axon protection. For example, poly-ADP ribosylation uses $\mathrm{NAD}^{+}$, influencing protein activity and cellular $\mathrm{NAD}^{+}$and $\mathrm{ATP}$ content, especially in response to stress ${ }^{33,34}$. Mild activation of PARP without $\mathrm{NAD}^{+}$depletion can be neuroprotective ${ }^{35}$. Another metabolite, NADPH, is a coenzyme for nitric oxide synthase, an enzyme linked to axon damage ${ }^{36}$, and synthesis of the signaling molecule cyclic ADP ribose from $\mathrm{NAD}^{+}$regulates calcium release from intracellular stores ${ }^{37}$, potentially influencing calcium activated proteases in Wallerian degeneration.

Both spontaneous and transgenic $W l d^{S}$ mice could be used to investigate the function of each parent gene. We already show that overexpression of Nmnat activity causes no overt phenotype, and report an in vivo mutation of a mammalian E4 ubiquitination factor. Despite the critical role played by the ubiquitin-proteasome pathway in neurological disease and many other processes, we know remarkably little about the function of such proteins.

Identification of the Wld gene facilitates studies to determine whether it protects axons in clinically relevant situations. The $W l d^{S}$ mutation is already known to protect neuronal processes in vitro from the toxic effects of vincristine ${ }^{13}$, indicating that traumatic and toxic axon death share a common final pathway. Current studies indicate that distal axon loss in myelin protein zero knockout mutants ${ }^{38}$ is rescued by $W l d^{S}$ (M. Samsam and R. Martini, unpublished data), and that $W l d^{S}$ protects in a mouse model of motoneuron disease (A. Ferri and A.C. Kato, unpublished data). Studies of $W l d^{S}$ in diverse neurological diseases is facilitated by our identification of the Wld gene and by recent protocols for tracking the inheritance of $W l d^{S}$ in crosses with neurological disease mutants ${ }^{39}$. Models of common and complex neurological disorders such as multiple sclerosis and diabetic neuropathy can now be investigated through the development of viral vectors for Wld and generation of transgenic $W l d^{S}$ rats. Mutational analysis in human neurological disorders with a homologous chromosomal location, such as hereditary Parkinsonism ${ }^{40}$, also becomes possible. Delayed Wallerian degeneration also alters the glial response to injury, as in a mouse model of spinal cord injury, where it delays inflammatory cell and astrocytic responses ${ }^{9,41}$. It may be that this information could be used to optimize tissue destruction and repair processes.

We conclude that the Wld gene is a chimera of $U b e 4 b$ and Nmnat encoding a predominantly nuclear protein in neurons, and we propose that other factors may mediate the protective effect on the axon. Axon protection is strongly dose-dependent and pyridine nucleotide metabolism is altered in the $W l d^{S}$ mouse. These findings open the way to a molecular understanding of Wallerian degeneration and to much-needed neuroprotective strategies that target not only the cell body, but also the axons and synaptic terminals. 
articles

\begin{abstract}
Methods
Generation of transgenic mice. Ube $4 b / N m n a t$ cDNA was RT-PCR amplified from $W l d^{S}$ brain using Platinum Pfx polymerase (Life Technologies, Karlsruhe, Germany) and cloned downstream of the $\beta$-actin promoter in pHßAPr-1 (ref. 42; Supplementary Fig. 3). Wld protein was thus expressed in neurons, where it has an intrinsic effect ${ }^{2,7,8}$, and other cell types, where $W l d^{S}$ mice also express it (Fig. 5). A 6-kb fragment containing promoter, cDNA and polyadenylation signal was released using NdeI and EcoRI and gel-purified using QIAquick extraction (Qiagen, Hilden, Germany). Pronuclear injection into CBA X C57 F1 single-cell embryos (G. Kollias, Vari, Greece) resulted in nine founders from 62 pups.
\end{abstract}

Genotyping of transgenic mice. DNA was prepared from a 5-mm tail biopsy using the Nucleon HT kit (Amersham Pharmacia, Freiburg, Germany). The 1.1-kb transgene coding region was detected using alkaline Southern blotting of a BamHI/HindIII double digest on Hybond N+ (Amersham Pharmacia) and hybridization with a corresponding ${ }^{32} \mathrm{P}$-labeled probe.

Sciatic nerve lesion. Six- to eleven-week-old mice were anesthetized intraperitoneally with Ketanest (100 mg/kg; Bayer, Leverkusen, Germany) and Rompun (5 mg/kg; Parke Davis/Pfizer, Karlsruhe, Germany). Right sciatic nerves (upper thigh) were transected and the wounds were closed with single sutures. Two to fourteen days later, mice were killed, the swollen first $2 \mathrm{~mm}$ of the distal nerve was discarded, the next $2 \mathrm{~mm}$ was used for light and electron microscopy, and a segment $4-10 \mathrm{~mm}$ distal to the lesion site was used in western blotting. Further distal nerves and muscles were used for electrophysiology.

Light and electron microscopy. Nerve segments were fixed for 1-3 days in fresh half-strength Karnovsky's fixation (4\% paraformaldehyde, $2 \%$ glutaraldehyde in $0.1 \mathrm{M}$ sodium cacodylate, $\mathrm{pH} 7.3$; ref. 43), extensively buffer-rinsed and osmicated for $4 \mathrm{~h}$ with $1 \% \mathrm{OsO}_{4}$ in $0.1 \mathrm{M}$ cacodylate. Samples were taken through a graded ethanol series including a uranylic acetate en bloc staining step overnight in $70 \%$ ethanol. Before infiltration with Araldite Cy212 epoxy resin (Serva, Heidelberg, Germany), propylene oxide was used as intermedium. Tissue blocks were cured for $60 \mathrm{~h}$ at $60^{\circ} \mathrm{C}$. Semithin $(0.5 \mu \mathrm{m})$ and thin $(60 \mathrm{~nm})$ cross-sections were taken on a Reichert Ultracut UCT ultramicrotome. Semithin sections for light microscopy were stained with methylene blue and thin sections, with $1 \%$ aqueous uranylic acetate $(20 \mathrm{~min})$, and sections were counterstained with Reynold's lead citrate $(7 \mathrm{~min})^{44}$. Thin sections were mounted on 150 mesh Formvar coated copper grids and examined with a Zeiss EM 902 electron microscope at $80 \mathrm{kV}$ acceleration voltage.

Neuromuscular junction electrophysiology and morphology. FDB and lumbrical muscles and contralateral controls were removed in Cologne and placed in cold physiological saline $\left(137 \mathrm{mM} \mathrm{Na}^{+}, 4 \mathrm{mM} \mathrm{K}^{+}, 2 \mathrm{mM}\right.$ $\mathrm{Ca}^{2+}, 1 \mathrm{mM} \mathrm{Mg}^{2+}, 147 \mathrm{mM} \mathrm{Cl}^{-}, 5 \mathrm{mM}$ glucose, $5 \mathrm{mM}$ HEPES, $\mathrm{pH} 7.2-7.4$, equilibrated with air or $100 \%$ oxygen). Electrophysiological experiments were done later the same day in Edinburgh, following transfer to a medium containing similar concentrations of $\mathrm{Na}^{+}, \mathrm{K}^{+}, \mathrm{Ca}^{2+}$ and $\mathrm{Mg}^{2+}$, plus $23 \mathrm{mM} \mathrm{HCO}_{3}^{-}, 2 \mathrm{mM} \mathrm{H}_{2} \mathrm{PO}_{4}^{-}$, equilibrated with $95 \% \mathrm{O}_{2} / 5 \%$ $\mathrm{CO}_{2}$. MEPPs and evoked synaptic responses to tibial nerve stimulation (EPPs) were recorded from FDB using an intracellular glass microelectrode and analyzed using WinWCP software ${ }^{45}$ (J. Dempster, University of Strathclyde). Recycled synaptic vesicles of motor nerve terminals were stained in lumbrical muscles using FM1-43 (Molecular Probes, Leiden, Netherlands) with $20 \mathrm{~Hz}$ nerve stimulation or depolarizing physiological solutions, and acetylcholine receptors subsequently stained with TRITC$\alpha$-bungarotoxin (Molecular Probes ${ }^{46,47}$. Endplates and terminals were examined in a Nikon fluorescence microscope (Kingston-upon-Thames, UK) using respectively a standard rhodamine filter cube and a customized cube with a $435 \mathrm{~nm}$ excitation filter, $455 \mathrm{~nm}$ dichroic mirror and a $10 \mathrm{~nm}$ bandpass $515 \mathrm{~nm}$ emission filter ${ }^{46}$.

Conventional immunocytochemical and fluorescent bungarotoxin probes were used for structural analysis. Muscle preparations, fixed for 60 min in $0.1 \mathrm{M} \mathrm{PBS}, 4 \%$ paraformaldehyde, were incubated in TRITC- $\alpha$ - bungarotoxin ( $5 \mu \mathrm{g} / \mathrm{ml} ; 30 \mathrm{~min}$ ) followed by overnight primary antibody (1:200 monoclonal anti-165 kDa neurofilament plus anti-synaptic vesicle antigen SV2, Developmental Studies Hybridoma Bank, University of Iowa; or affinity purified rabbit polyclonal N70; see below). Secondary antibodies (1:200 dilution; $4 \mathrm{~h}$ ) were FITC-conjugated sheep-anti-mouse IgG or anti-rabbit IgG (Diagnostics Scotland). Preparations were mounted in Vektashield (Vector Labs, Burlingame, California) and viewed in a fluorescence microscope using a Leitz 50× water immersion objective lens (NA 1.00; Wetzlar, Germany). Most images were captured with a Hamamatsu C5810 chilled color CCD camera and acquired using Openlab software (Improvision, Coventry, UK). Confocal images were obtained using a BioRad Radiance 2000 system (Hemel Hempstead, UK).

Western blotting. We analyzed Wld protein expression level in mouse brains homogenized in two volumes of $20 \mathrm{mM}$ HEPES ( $\mathrm{pH}$ 7.5), $0.2 \mathrm{M}$ $\mathrm{CaCl}_{2}, 0.2 \mathrm{M} \mathrm{MgSO}_{4}, 1 \mathrm{ml} / 20 \mathrm{~g}$ tissue protease inhibitor cocktail (Sigma, Taufkirchen, Germany) and $1 \mathrm{mg} / \mathrm{ml}$ DNase (Sigma). Cytoskeletal protein preservation was determined in lesioned sciatic nerves homogenized in 20 volumes of this buffer. Proteins were separated using standard SDS-PAGE and semi-dry blotted onto nitrocellulose. Loading and transfer were checked using Ponceau S (Sigma) and Coomassie Blue. Primary antibodies were applied (overnight, $4^{\circ} \mathrm{C}$ ) followed by horseradish peroxidase-coupled secondary antibody ( $1 \mathrm{~h}$, room temperature; goat-anti-mouse 1:3,000, goat-anti-rabbit 1:5,000; Dianova, Hamburg, Germany) and detection using enhanced chemiluminescence (Amersham Pharmacia). Chimeric protein expression was quantified using affinity-purified N70 antibody (below) and $\beta$-tub 2.1 (Sigma) control and Quantity One software (BioRad). Cytoskeletal protein degradation was analyzed using phosphate-independent monoclonal N52 (1:2,000; Sigma) against heavy neurofilament protein.

Morphological quantification of axon preservation. We counted 5001500 myelinated axons in randomly chosen fields $2-4 \mathrm{~mm}$ distal to a sciatic nerve lesion in transverse semithin sections on a Zeiss Axiophot microscope (Göttingen, Germany) coupled to a digital camera. Survival criteria were normal myelin sheaths, uniform axoplasm and intact mitochondria, supported by electron microscopy spotchecks. Scoring was documented with Meta Imaging software (Universal Imaging Corporation, Downingtown, Pennsylvania). Standard errors of the mean and $t$ tests were calculated using SPSS for Windows 10.0.

Cloning and expression of recombinant proteins. Constructs were generated to express in bacteria the $\mathrm{N}$-terminal 70 amino acids (N70) of the chimeric protein and full-length chimeric protein. Inserts were PCRamplified from transgene construct using Pfx polymerase (Life Technologies). Primers for N70 were5'-GACTAGCTAGCATGGAGGAGCTGA GCGCTGAC-3' and 5' ${ }^{\prime}$-ATCCGCTCGAGCTAGTCTGCTGCACCTATG GGGGA-3'.

For full-length chimeric cDNA, the second primer was replaced by $5^{\prime}$ CGCCTCGAGTCACAGAGTGGAATGGTTGTGC-3'.

Products were ligated into NheI/XhoI double-digested pET-28b (+) vector (Novagen, Schwalbach, Germany) and transformed into XL-10 Gold (Stratagene, Amsterdam, Netherlands). Plasmids isolated using the Plasmid Mini Kit (Qiagen) were retransformed into BL21 (DE3) (Novagen). Protein expression was induced with $1 \mathrm{mM}$ IPTG for $3 \mathrm{~h}$ at $\mathrm{OD}_{600}=0.8$. For analysis of Nmnat activity, cells were lysed by sonication.

Generation of polyclonal antisera. The N70 bacterial pellet was resuspended in native binding buffer $(20 \mathrm{mM}$ sodium phosphate, $500 \mathrm{mM}$ sodium chloride $\mathrm{pH} 7.8,100 \mu \mathrm{g} / \mathrm{ml}$ egg white lysozyme), sonicated on ice $(6 \times 15 \mathrm{~s}$ with 15 -s intervals) and centrifuged $(3,000 \mathrm{~g}, 15 \mathrm{~min})$. N70 was purified using a ProBond column (Invitrogen, Groningen, Netherlands) and concentrated using a YM-3 Centricon centrifugal filter (Millipore, Bedford, Massachusetts). Antisera were raised by intradermal immunization of two SPF-rabbits by Eurogentec (Seraing, Belgium) with boosts at days 14, 28 and 56, and a final bleed at 80 days.

For affinity purification $500 \mu \mathrm{g}$ N70 protein bound to ProBond resin ( $2 \mathrm{ml}$ wet volume) was blocked with $5 \%(\mathrm{w} / \mathrm{v})$ dried skimmed milk powder plus $1 \%(\mathrm{w} / \mathrm{v})$ BSA in native binding buffer. Resin was incubated with crude antiserum ( $2 \mathrm{ml}$ in $8 \mathrm{ml}$ binding buffer), and washed with 10 
bed volumes binding buffer. Specific antibodies, binding only Wld protein and Ube4b, were eluted with $100 \mathrm{mM}$ ethanolamine ( $\mathrm{pH}$ 11.5), neutralized with $1.5 \mathrm{M}$ Tris and dialyzed against PBS.

Immunocytochemistry of spinal cord, nerves and brain. Perfusionfixed tissues were fixed for a further four hours in $4 \%$ paraformaldehyde, 0.1 M PBS before embedding in paraffin. Paraffin sections on poly-L-lysine coated slides were dewaxed, washed in PBS, rinsed in citrate buffer overnight $\left(60^{\circ} \mathrm{C}\right)$ and incubated with $0.1 \%$ Triton $\mathrm{X}-100$ (Sigma). After blocking (5\% BSA in PBS), the following primary antibodies were applied (overnight, $4^{\circ} \mathrm{C}$ ): affinity purified N70 (above), plus monoclonal anti-MAP2 (Sigma), mouse polyclonal anti-GFAP (Sigma) or monoclonal anti-neurofilament (Biogenex, San Ramon, California). Secondary antibodies ( $1 \mathrm{~h}$, room temperature) were either Cy3-labeled goat-anti-rabbit (Dako, Hamburg, Germany) or Texas Red-labeled goat-anti-rabbit (Molecular Probes) together with Cy2labeled goat-anti-mouse (both Dako), diluted according to the manufacturers' instructions.

Determination of NMNAT activity. Mice were killed, and whole brains were immediately removed and cut into two equal hemispheres for NMNAT assay and $\mathrm{NAD}^{+}$determination, respectively. Tissue was suspended in 3 volumes of $100 \mathrm{mM}$ Tris- $\mathrm{HCl}, \mathrm{pH} 7.4,0.5 \mathrm{mM}$ EDTA, $1 \mathrm{mM}$ $\mathrm{MgCl}_{2}, 1 \mathrm{mM}$ DTT, $1 \mathrm{mM}$ PMSF and homogenized on ice $(3 \times 3 \mathrm{~s}$ with 10 -s intervals) using an Ultra-Turrax homogenizer at medium speed. NMNAT activity was determined using a reaction mixture of $40 \mathrm{mM}$ Tris- $\mathrm{HCl} \mathrm{pH}$ 7.5, $5 \mathrm{mM}$ nicotinamide mononucleotide (NMN), $3.4 \mathrm{mM}$ ATP, $18 \mathrm{mM} \mathrm{MgCl}_{2}, 10 \mathrm{mM} \mathrm{NaF}$, and brain homogenate (final volume of $0.5 \mathrm{ml})$. The reaction was started by the addition of $\mathrm{NMN}$ at $37^{\circ} \mathrm{C}$ and stopped after 10-40 min by adding $100 \mu \mathrm{l}$ of assay mixture to $50 \mu \mathrm{l}$ of ice-cold $1.2 \mathrm{M} \mathrm{HClO}_{4}$. After $10 \mathrm{~min}$, at $0^{\circ} \mathrm{C}$ the mixture was centrifuged and $130 \mu \mathrm{l}$ of supernatant was neutralized by addition of $35 \mu \mathrm{l} 0.8-\mathrm{M}$ $\mathrm{K}_{2} \mathrm{CO}_{3}$. NMNAT activity was calculated after HPLC identification and quantification of $\mathrm{NAD}^{+}$produced ${ }^{48}$. One unit of enzyme activity catalyses the synthesis of $1 \mu \mathrm{mol}$ of $\mathrm{NAD}^{+}$per minute at $37^{\circ} \mathrm{C}$.

Determination of $\mathrm{NAD}^{+}$content. A brain hemisphere in 2 volumes $7.5 \%$ ice-cold $\mathrm{HClO}_{4}$ was homogenized using an Ultra-Turrax $(4 \times 4 \mathrm{~s}$, with $20 \mathrm{~s}$ intervals). After $15 \mathrm{~min}$ at $0^{\circ} \mathrm{C}$, the suspension was centrifuged at $16,000 \mathrm{~g}$ for $1 \mathrm{~min}$. The $\mathrm{pH}$ was adjusted to 6.0 using $0.8 \mathrm{M} \mathrm{K}_{2} \mathrm{CO}_{3}$. After centrifugation, the extract was analyzed by HPLC ${ }^{48}$.

Animal experimentation was approved by Stadt Köln Veterinäramt, licence $\mathrm{K} 13,11 / / 00$.

GenBank accession numbers. The GenBank accession number for NMNAT is AF312734; for Wld, AF260924.

Note: Supplementary figures are available on the Nature Neuroscience web site (http://neuroscience.nature.com/web_specials).

\section{ACKNOWLEDGementS}

We thank E. Janssen, C. Hoffmann (Department of Anatomy I, University of Cologne), F. Carnevali, F. Pierella (University of Ancona), S. Fearn and M. Botham (University of Southampton) for technical assistance, T. Vogt for supplying $p H \beta A P r-1$ plasmid and $R$. Martini for critically reading the manuscript. This work was supported by the Federal Ministry of Education and Research (FKZ: 01 KS 9502) and Center for Molecular Medicine, University of Cologne (ZMMK) (T.G.A.M., W.M., D.W., M.P.C.), a Wellcome Trust Biomedical Collaboration Grant (R.R.R., M.P.C.) and Consiglio Nazionale delle Ricerche Target Project "Biotechnology" (M.E., G.M.).

\section{ReCeived 27 SePteMber; ACCePted 31 OCTOBER 2001}

1. Waller, A. Experiments on the section of glossopharyngeal and hypoglossal nerves of the frog and observations of the alternatives produced thereby in the structure of their primitive fibres. Phil. Trans. R. Soc. Lond. 140, 423-429 (1850).
2. Deckwerth, T. L. \& Johnson, E. M. Jr. Neurites can remain viable after destruction of the neuronal soma by programmed cell death (apoptosis). Dev. Biol. 165, 63-72 (1994).

3. Finn, J. T. et al. Evidence that Wallerian degeneration and localized axon degeneration induced by local neurotrophin deprivation do not involve caspases. J. Neurosci. 20, 1333-1341 (2000).

4. Lunn, E. R., Perry, V. H., Brown, M. C., Rosen, H. \& Gordon, S. Absence of Wallerian degeneration does not hinder regeneration in peripheral nerve. Eur. J. Neurosci. 1, 27-33 (1989).

5. Perry, V. H., Lunn, E. R., Brown, M. C., Cahusac, S. \& Gordon, S. Evidence that the rate of Wallerian degeneration is controlled by a single autosomal dominant gene. Eur. J. Neurosci. 2, 408-413 (1990).

6. Perry, V. H., Brown, M. C. \& Lunn, E. R. Very slow retrograde and Wallerian degeneration in the CNS of C57BL/Ola mice. Eur. J. Neurosci. 3, 102-105 (1991).

7. Glass, J. D., Brushart, T. M., George, E. B. \& Griffin, J. W. Prolonged survival of transected nerve fibres in C57BL/Ola mice is an intrinsic characteristic of the axon. J. Neurocytol. 22, 311-321 (1993).

8. Buckmaster, E. A., Perry, V. H. \& Brown, M. C. The rate of Wallerian degeneration in cultured neurons from wild type and C57BL/Wld ${ }^{S}$ mice depends on time in culture and may be extended in the presence of elevated $\mathrm{K}^{+}$levels. Eur. J. Neurosci. 7, 1596-1602 (1995).

9. Zhang, Z., Fujiki, M., Guth, L. \& Steward, O. Genetic influences on cellular reactions to spinal cord injury: a wound-healing response present in normal mice is impaired in mice carrying a mutation $\left(W l d^{S}\right)$ that causes delayed Wallerian degeneration. J. Comp. Neurol. 371, 485-495 (1996).

10. Dal Canto, M. C. \& Gurney, M. E. Neuropathological changes in two lines of mice carrying a transgene for mutant human $\mathrm{Cu}, \mathrm{Zn}$ SOD, and in mice overexpressing wild type human SOD: a model of familial amyotrophic lateral sclerosis (FALS). Brain Res. 676, 25-40 (1995).

11. Perry, V.H. \& Anthony, D.C. Axon damage and repair in multiple sclerosis. Phil. Trans. R. Soc. Lond. B Biol. Sci. 354, 1641-1647 (1999).

12. Glynn, P. Neural development and neurodegeneration: two faces of neuropathy target esterase. Prog. Neurobiol. 61, 61-74 (2000).

13. Wang, M. S., Wu, Y., Culver, D. G. \& Glass, J. D. The gene for slow Wallerian degeneration $\left(W l d^{S}\right)$ is also protective against vincristine neuropathy. Neurobiol. Dis. 8, 155-161 (2001).

14. Sagot, Y. et al. Bcl-2 overexpression prevents motoneuron cell body loss but not axonal degeneration in a mouse model of a neurodegenerative disease. J. Neurosi. 15, 7727-7733 (1995).

15. Houseweart, M. K. \& Cleveland, D. W. Bcl-2 overexpression does not protect neurons from mutant neurofilament-mediated motor neuron degeneration. J. Neurosci. 19, 6446-6456 (1999).

16. Coleman, M. P. et al. An $85-\mathrm{kb}$ tandem triplication in the slow Wallerian degeneration (Wld ${ }^{S}$ ) mouse. Proc. Natl. Acad. Sci. USA 95, 9985-9990 (1998).

17. Lyon, M. F., Ogunkolade, B. W., Brown, M. C., Atherton, D. J. \& Perry, V. H. A gene affecting Wallerian nerve degeneration maps distally on mouse chromosome 4. Proc. Natl. Acad. Sci. USA 90, 9717-9720 (1993).

18. Conforti, L. et al. A Ufd2/D4Cole1e chimeric protein and overexpression of Rbp7 in the slow Wallerian degeneration $\left(\right.$ Wld $\left.^{S}\right)$ mouse. Proc. Natl. Acad. Sci. USA 97, 11377-11382 (2000).

19. Emanuelli, M. et al. Human NMN adenylyltransferase: molecular cloning, chromosomal localization, tissue mRNA levels, bacterial expression, and enzymatic properties. J. Biol. Chem. 276, 406-412 (2001).

20. Magni, G., Amici, A., Emanuelli, M., Raffaelli, N. \& Ruggieri, S. Enzymology of $\mathrm{NAD}^{+}$synthesis. Adv. Enzymol. Relat. Areas Mol. Biol. 73, 135-182 (1999).

21. Conforti, L. et al. The major brain isoform of Kiflb lacks the putative mitochondria-binding domain. Mamm. Genome 10, 617-622 (1999).

22. Zhao, C. et al. Charcot-Marie-Tooth disease type 2 a caused by mutation in a microtubule motor kif1bbeta. Cell 105, 587-597 (2001).

23. Ribchester, R. R. et al. Persistence of neuromuscular junctions after axotomy in mice with slow Wallerian degeneration $\left(\mathrm{C} 57 \mathrm{BL} / W l d^{\mathrm{S}}\right)$. Eur. J. Neurosci. 7, 1641-1650 (1995).

24. Gillingwater, T. H. \& Ribchester, R. R. Age-dependent synapse withdrawal at axotomised neuromuscular junctions in $W l d^{S}$ mutant mice. J. Physiol. (Lond.) 523P, 53P (2000).

25. Gillingwater, T. H. \& Ribchester, R. R. Compartmental neurodegeneration and synaptic plasticity in the $W l d^{S}$ mutant mouse. J. Physiol. (Lond.) 534 , 627-639 (2001)

26. Feng, G. et al. Imaging neuronal subsets in transgenic mice expressing multiple spectral variants of GFP. Neuron 28, 41-51 (2000).

27. Brown, M. C., Booth, C. M., Lunn, E. R. \& Perry, V. H. Delayed response to denervation in muscles of C57BL/Ola mice. Neuroscience 43, 279-283 (1991).

28. Sagot, Y., Tan, S. A., Hammang, J. P., Aebischer, P. \& Kato, A. C. GDNF slows loss of motoneurons but not axonal degeneration or premature death of $\mathrm{pmn} / \mathrm{pmn}$ mice. J. Neurosci. 16, 2335-2341 (1996).

29. Burne, J. F., Staple, J. K. \& Raff, M. C. Glial cells are increased proportionally in transgenic optic nerves with increased numbers of axons. J. Neurosci. 16, 2064-2073 (1996).

30. Koegl, M. et al. A novel ubiquitination factor, E4, is involved in multiubiquitin chain assembly. Cell 96, 635-644 (1999).

31. Saigoh, K. et al. Intragenic deletion in the gene encoding ubiquitin carboxyterminal hydrolase in gad mice. Nat. Genet. 23, 47-51 (1999). 


\section{articles}

32. Hamilton, M. H., Tcherepanova, I., Huibregtse, J. M. \& McDonnell, D. P Nuclear import/export of hRPF1/Nedd4 regulates the ubiquitin-dependen degradation of its nuclear substrates. J. Biol. Chem. 276, 26324-26331 (2001).

33. Smith, S. The world according to PARP. Trends Biochem. Sci. 26, 174-179 (2001).

34. Ha, H.C. \& Snyder, S.H. Poly(ADP-ribose) polymerase is a mediator of necrotic death by ATP depletion. Proc. Natl. Acad. Sci. USA 96, 13978-13982 (1999).

35. Nagayama, T. et al. Activation of poly(ADP-ribose) polymerase in the rat hippocampus may contribute to cellular recovery following sublethal transient global ischemia. J. Neurochem. 74, 1636-1645 (2000).

36. Smith, K. J., Kapoor, R., Hall, S. M. \& Davies, M. Electrically active axons degenerate when exposed to nitric oxide. Ann. Neurol. 49, 470-476 (2001).

37. Di Lisa, F. \& Ziegler, M. Pathophysiological relevance of mitochondria in $\mathrm{NAD}(+)$ metabolism. FEBS Lett. 492, 4-8 (2001).

38. Frei, R. et al. Loss of distal axons and sensory Merkel cells and features indicative of muscle denervation in hindlimbs of $\mathrm{P} 0$-deficient mice. J. Neurosci. 19, 6058-6067 (1999).

39. Mi, W., Conforti, L. \& Coleman, M. P. Genotyping methods to detect a unique neuroprotective factor for axons ( $\left.W l d^{\mathrm{S}}\right)$. J. Neurosci. Methods (in press).

40. Valente, E.M. et al. Localization of a novel locus for autosomal recessive earlyonset parkinsonism, PARK6, on human chromosome 1p35-p36. Am. J. Hum. Genet. 68, 895-900 (2001)
41. Fujiki, M., Zhang, Z., Guth, L. \& Steward, O. Genetic influences on cellular reactions to spinal cord injury: activation of macrophages/microglia and astrocytes is delayed in mice carrying a mutation $\left(W l d^{S}\right)$ that causes delayed Wallerian degeneration. J. Comp. Neurol. 371, 469-484 (1996).

42. Gunning, P., Leavitt, J., Muscat, G., Ng, S. Y. \& Kedes, L. A human beta-actin expression vector system directs high-level accumulation of antisense transcripts. Proc. Natl. Acad. Sci. USA 84, 4831-4835 (1987).

43. Karnovsky, M. J. A formaldehyde-glutaraldehyde fixative of high osmolarity for use in electron microscopy. J. Cell Biol. 27, 137A (1965).

44. Reynolds, E. E. The use of lead citrate at high $\mathrm{pH}$ as an electron opaque stain in electron microscopy. J. Cell Biol. 17, 208 (1963).

45. Costanzo, E. M., Barry, J. A. \& Ribchester, R. R. Co-regulation of synaptic efficacy at stable polyneuronally innervated neuromuscular junctions in reinnervated rat muscle. J. Physiol. (Lond.) 521, 365-374 (1999).

46. Costanzo, E. M., Barry, J. A. \& Ribchester, R. R. Competition at silent synapses in reinnervated skeletal muscle. Nat. Neurosci. 3, 694-700 (2000).

47. Ribchester, R. R., Mao, F. \& Betz, W. J. Optical measurements of activitydependent membrane recycling in motor nerve terminals of mammalian skeletal muscle. Proc. R. Soc. Lond. B Biol. Sci. 255, 61-66 (1994).

48. Balducci, E. et al. Assay methods for nicotinamide mononucleotide adenylyltransferase of wide applicability. Anal. Biochem. 228, 64-68 (1995). 